\title{
ETIOLOGIA
}

\section{La percepción materna del cólico infantil es un fenómeno social}

The Social Origin of Infantile Colic. Crowcroft N, Strachan D. BMJ 1997:314:1325-1328.

\section{Objetivo}

Estudiar la prevalencia y factores de riesgo del cólico de la infancia (CI) en la población general.

\section{Diseño}

Estudio de corte transversal a través de cuestionarios administrados por agentes de salud.

\section{Lugar}

Inglaterra

\section{Pacientes}

Se incluyeron 67.172 madres de lactantes de 24 a 37 días de edad nacidos entre 1975 y 1988. Análisis secundario de datos de un estudio de factores de riesgo de muerte súbita en lactantes.

\section{Evaluación de factores pronósticos}

Se analizaron: peso, alimentación y comportamiento del lactante; paridad materna, edad y características socioeconómicas de los padres (vecindario, vivienda, edad materna al finalizar su educación formal y ocupación de los padres).

Medición de resultados principales

Percepción materna de cólico en el momento de la entrevista y el número de días que había tenido cólico desde el nacimiento. El cólico no fue formalmente definido, dejando a la madre la interpretación del mismoe

\section{Comentario}

El CI se define como paroxismos de llanto o irritabilidad que duran tres o más horas por día, tres o más días de la semana.(1) Esta es la definición más rigurosa para hacer comparaciones entre distintas poblaciones y/o estudios. Sin embargo, establecer a la percepción materna de que el niño llora inconsolablemente como variable de estudio puede ser más útil en la práctica clínica. El Cl puede no ser una entidad específica sino una variante extrema del 1lanto normal. También puede resultar de fenómenos alérgicos, intolerancia a la leche de vaca, peristalsis anormal o flatulencia. La teoría interaccional postula la presencia no sólo del exceso de llanto infantil, sino también de la incapacidad de los padres para consolarlo (2). Sigue siendo controvertido el rol que juega la ansiedad materna. La prevalencia fue similar a la reportada en la literatura $(10$ a $20 \%)(1$ y 3$)$. La mayor fortaleza del estudio es haber tenido una muestra de 67.172 sujetos, que brinda un gran poder para poner a prueba la hipótesis nula de que los bebes con CI no son diferentes de los que no lo tienen. El poder no está aclarado en el diseño, lo que podría motivarnos a pensar que algunas de estas asociaciones hayan sido encontradas "yendo de pesca" ( $\sin$ haberlas ido a buscar con una hipótesis previa) entre los datos de un estudio diseñado para otra cosa. Este tipo de estudios puede ser muy util para generar nuevas hipótesis a evaluar en estudios más rigurosos. Esto puede también ser un punto a favor, ya que al ser el objetivo principal de la encuesta establecer los factores de riesgo para muerte súbita, disminuye el sesgo del recuerdo debido a que en la encuesta hay preguntas de otras cosas mezcladas con las que interrogan sobre el CI. Al ser un estudio de corte transversal, no se

\section{Resultados principales}

La prevalencia de CI fue del 18.3\%. Se encontró asociación significativa de CI con: a) Mejor estado de la vivienda: muy buen estado vs. muy mal estado, OR 1.79 (IC 95\% 1.18 a 2.71); b) Mayor edad materna: las >44 vs. <20, OR 2.39 (IC 95\% 1.09 a 5.24); c) Mayor edad de la madre al terminar su educación formal: terminar luego de los 18 años vs. antes de los 15 años, OR 1.50 (IC $95 \% 1.26$ a 1.79). La asociación fue negativa con: a) El aumento de la paridad: más de 5 hijos vs. primíparas OR 0.59 (IC 95\% 0.46 a 0.75 ); b) Recibir fórmula vs. lactancia, OR 0.92 (IC $95 \% 0.87$ a 0.98$)$.

\section{Conclusiones}

La percepción materna del cólico de la infancia es un fenómeno social. Las primigrávidas mayores con una ocupación no manual y con mayor educación formal tienen una mayor tasa de reporte de CI. Estos hallazgos son consistentes con la hipótesis de que la interacción padres/hijo, a diferencia de la alimentación, es importante en condicionar la percepción del CI.

Fuente de financiamiento: No referida

debería hablar de factores de riesgo sino de asociaciones, ya que sólo puede hablarse de riesgo en estudios prospectivos, en los que uno puede saber que el factor de riesgo antecede al evento. Este artículo aporta evidencia en contra de las intervenciones dietéticas como estrategia frente al CI. Podrían relativizarse algunas de las asociaciones socioeconómicas encontradas, ya que los grupos de mayor nivel socioeconómico tienen más tendencia a reportar la percepción de eventos negativos para la salud. Sin embargo, de acuerdo a la teoría interaccional, podría inferirse que las madres de mayor edad, menos hijos y de mejor nivel socioeconómico tienen más dificultades para consolar a sus niños cuando lloran o menor tolerancia frente a su llanto.

\section{Dr. Sergio Terrasa Unidad de Medicina Familiar y Preventiva Hospital Italiano de Buenos Aires}

Dr. Sebastián Fernández

\section{Referencias}

1. Geeta Grover. Crying and colic. Pediatrics a a primary care aprproach Berkowitz CD. 1996; 26:102-4 by WB Saunders Company

2. Rautva P, Helenius H, Lehtonen L. Phychosocial predisposing factors for infantile colic. BMJ 1993; 307:600-4

3. Hide DN, Guyer BM. Prevalence of infantile colic Arch. Dis. Child 1982: 57:559-60 